\title{
Pemberian Pupuk Organik Cair Kotoran Kambing Dalam Meningkatkan Hasil Terung (Solanum melongena, L.)
}

\author{
Ratri Yulianingsih \\ Fakultas Pertanian Universitas Kapuas Sintang \\ email: ratriyulianingsih2957@gmail.com
}

\begin{abstract}
Abstrak: Pemanfaatan bahan organik kotoran kambing perlu diberikan pada tanaman melalui tanah dengan kandungan bahan organik dan unsur hara rendah. Supaya bahan organik tanah bertambah serta unsur hara di dalamnya dapat terserap oleh tanaman maka pupuk kandang diberikan dalam bentuk pupuk organik cair. Penelitian ini ingin mengetahui pengaruh pemberian pupuk organik cair kotoran kambing dalam meningkatkan hasil tanaman terung. Penelitian ini menggunakan metode percobaan lapangan, percobaan dilakukan dengan menggunakan Rancangan Acak Kelompok. Perlakuan pada penelitian ini adalah POC kotoran kambing, yang terdiri dari lima taraf yaitu: $\mathrm{P}_{0}$ (tanpa POC kotoran kambing), $\mathrm{P}_{1}(4 \mathrm{ml}), \mathrm{P}_{2}(8 \mathrm{ml}), \mathrm{P}_{3}(12 \mathrm{ml}), \mathrm{P}_{4}(16 \mathrm{ml})$. Data hasil penganatan dianalisis dengan uji $\mathrm{F}$ dan dilanjutkan dengan uji BNJ. Hasil penelitian diketahui bahwa pemberian pupuk organik cair kotoran kambing sebanyak $16 \mathrm{ml}$ dapat meningkatkan hasil tanaman terung dengan jumlah buah rata-rata 4,90 buah dan berat buah rata-rata $0,44 \mathrm{~kg}$ per tanaman.

Kata kunci: POC kotoran kambing, Hasil, Terung
\end{abstract}

\section{PENDAHULUAN}

Terung (Solanum melongena) merupakan sayuran buah. Menurut Soetassad, dkk (2003) sayuran ini digemari oleh banyak orang karena rasanya yang enak, harganya yang terjangkau, selain itu terung mengandung karbohidrat, mineral, vitamin $\mathrm{A}, \mathrm{B}$, dan $\mathrm{C}$.

Rendahnya produksi hasil petanian khususnya tanaman hortikultura, trmasuk terung, diduga karena keterbatasan pengetahuan petani tentang teknik budidaya yang baik, dan tanah sebagai tempat tumbuh yang kurang subur.

Tanah PMK dikenal dengan tanah yang kurang subur karena mengandung bahan organik sedikit, $\mathrm{pH}$ rendah, $\mathrm{Al}$ dan $\mathrm{Fe}$ tinggi. Agar tanah PMK dapat dikelola sebagai lahan tanaman sayur perlu diberikan pupuk organik berupa pupuk organik cair kotoran kambing.

Pupuk organik cair kotoran kambing merupakan pupuk yang berasal dari hasil fermentasi kotoran kambing dengan $\mathrm{EM}_{4}$. Musnamar 
Pemberian Pupuk Organik Cair Kotoran Kambing Dalam Meningkatkan Hasil Terung (Salanum melongena, L.)

(2007) menyatakan bahwa pupuk organik dapat memperbaiki kesuburan tanah dan tidak meninggalkan dampak negatif pada hasil tanaman sehingga aman bagi kesehatan manusia. Pada umumnya kotoran kambing diberikan dalam bentuk padat tanpa diolah terlebih dahulu sehingga dapat mengakibatkan tumbuhnya jamur dan menyebabkan tanaman menjadi layu, bahkan mati.

Salah satu alternatif pengolahan kotoran kambing adalah dengan dibuat POC, sampai saat ini belum begitu banyak pemanfaatan kotoran kambing yang diolah menjadi POC, padahal dengan diolah menjadi POC kotoran padat tersebut dapat disimpan dalam waktu yang lama dan lebih efisien (Setiawan, 2007).

Penelitian ini bertujuan untuk mengetahui pengaruh pemberian pupuk organik cair kotoran kambing dalam meningkatkan hasil tanaman terung.

\section{METODOLOGI PENELITIAN}

Penelitian ini menggunakan metode percobaan lapangan dengan Rancangan Acak Kelompok. Perlakuan pada penelitian ini adalah POC kotoran kambing, yang terdiri dari lima taraf dengan 5 kali pengulangan. Taraf perlakuan terdiri dari: $\mathrm{P}_{0}=$ tanpa POC kotoran kambing; $\mathrm{P}_{1}=4 \mathrm{ml}$ POC kotoran kambing per liter air; $\mathrm{P}_{2}=8 \mathrm{ml} \mathrm{POC}$ kotoran kambing per liter air, $\mathrm{P}_{3}=12$ ml POC kotoran kambing per liter air, $\mathrm{P}_{4}=16 \mathrm{ml}$ POC kotoran kambing per liter air.

Data hasil pengamatan dianalisis dengan uji $\mathrm{F}$ kemudian dilanjutkan dengan uji BNJ pada selang kepercayaan 0,05 dan 0,01.

\section{HASIL DAN PEMBAHASAN}

Hasil

Hasil pengamatan pemberian POC kotoran kambing terhadap peubah yang diamati tertera pada Tabel 1. 
Tabel 1. Rerata Hasil Pengamatan Pemberian POC Kotoran Kambing Terhadap Peubah Jumlah Buah Dan Berat Buah

\begin{tabular}{lrcc}
\hline \multirow{2}{*}{ Perlakuan } & \multicolumn{2}{c}{ Rerata } \\
\cline { 2 - 3 } & & Jumlah Buah & Berat Buah (kg) \\
\hline $\mathrm{P}_{0}$ & 1,00 & & 0,06 \\
$\mathrm{P}_{1}$ & 2,20 & 0,17 \\
$\mathrm{P}_{2}$ & 2,95 & 0,25 \\
$\mathrm{P}_{3}$ & 4,25 & 0,36 \\
$\mathrm{P}_{4}$ & 4,90 & 0,44 \\
\hline
\end{tabular}

Sumber: Hasil Pengamatan, 2019

Tabel 1 menampilkan rerata jumlah buah tertinggi terlihat pada tanaman $\mathrm{P}_{4}$ yaitu rata-rata 4,90 buah per tanaman, sedangkan jumlah buah terendah pada tanaman $\mathrm{P}_{0}$ yaitu 1,00 buah per tanaman. Berat buah tertinggi pada tanaman $\mathrm{P}_{4}$ yaitu ratarata $0,44 \mathrm{~kg}$ per tanaman, sedangkan berat buah terendah pada tanaman $\mathrm{P}_{0}$ yaitu $0,06 \mathrm{~kg}$ per tanaman.

Hasil uji $\mathrm{F}$ menyatakan pemberian POC kotoran kambing berpengaruh terhadap hasil terung, terlihat pada peubah jumlah buah dan berat buah, seperti ditampilkan pada Tabel 2.

Tabel 2. Uji F Pemberian POC Kotoran Kambing Terhadap Peubah Jumlah Buah Dan Berat Buah

\begin{tabular}{llllll}
\hline \multirow{2}{*}{ SK } & F Hitung & \multicolumn{3}{c}{ F Tabel } \\
\cline { 2 - 5 } & Jumlah Buah & $\begin{array}{l}\text { Berat } \\
(\mathbf{k g})\end{array}$ & Buah & $\mathbf{0 , 0 5}$ & $\mathbf{0 , 0 1}$ \\
\hline Kelompok & $2,48^{\text {tn }}$ & $5,146^{* *}$ & 3,01 & 4,77 \\
Perlakuan & $66,08^{* *}$ & $178,94^{* *}$ & 3,01 & 4,77 \\
\hline
\end{tabular}

Sumber: Hasil Analisis Data, 2019

Keterangan: $\mathrm{tn}=$ tidak nyata pada taraf 0,05

$* *$ = nyata pada taraf 0,01

Hasil analisis ragam pada pada taraf 0,01 sehingga dilanjutkan Tabel 2 diketahui bahwa POC uji BNJ, hasilnya disajikan pada kotoran kambing berpengaruh nyata Tabel 3. 
Pemberian Pupuk Organik Cair Kotoran Kambing Dalam Meningkatkan Hasil Terung (Salanum melongena, L.)

Tabel 3. Uji BNJ Pemberian POC Kotoran Kambing Terhadap Peubah Jumlah Buah Dan Berat Buah

\begin{tabular}{lll}
\hline Perlakuan & Jumlah Buah & Berat Buah $(\mathbf{k g})$ \\
\hline $\mathrm{P}_{0}$ & $1,00 \mathrm{a}$ & $0,06 \mathrm{a}$ \\
$\mathrm{P}_{1}$ & $2,20 \mathrm{~b}$ & $0,17 \mathrm{~b}$ \\
$\mathrm{P}_{2}$ & $2,95 \mathrm{c}$ & $0,25 \mathrm{c}$ \\
$\mathrm{P}_{3}$ & $4,25 \mathrm{~d}$ & $0,36 \mathrm{~d}$ \\
$\mathrm{P}_{4}$ & $4,90 \mathrm{e}$ & $0,44 \mathrm{e}$ \\
\hline BNJ 0,05 & 0,35 & 0,02 \\
\hline BNJ 0,01 & 0,45 & 0,03 \\
\hline
\end{tabular}

Sumber: Hasil Analisis Data, 2019

Keterangan: angka yang ditandai huruf berbeda menunjukkan beda nyata pada taraf 0,01

Hasil uji BNJ pada Tabel 3 menunjukkan bahwa jumlah buah dan berat buah per tanaman mengikuti taraf pemberian POC kotoran kambing, semakin tinggi dosis perlakuan maka semakin meningkat jumlah buah dan berat buah yang dihasilkan oleh tanaman.

\section{Pembahasan}

Pemberian POC kotoran kambing berpengaruh nyata terhadap jumlah buah dan berat buah per tanaman. Pengaruh nyata ini dimungkinkan karena dengan adanya pemberian POC kotoran kambing tersebut menyebabkan semakin banyak unsur hara yang disuplai bagi tanaman terung. Unsur-unsur hara ini dapat disuplai karena membaiknya kondisi tanah PMK baik struktur maupun tekstur tanah sehingga akar tanaman berkembang dengan baik. Setyamidjaja (2006:83) menyatakan bahwa pemberian pupuk organik menyebabkan porositas dan aerasi tanah menjadi lebih baik sehingga perkembangan dan pertumbuhan tanaman terutama akar dapat menjangkau unsur hara dalam tanah.

Hasil uji BNJ diketahui bahwa pemberian $16 \mathrm{ml}$ pupuk organik cair kotoran kambing menghasilkan tinggi tanaman jumlah buah dan berat buah tertinggi. Hal ini diduga karena bahan organik dan unsur hara pada tanah PMK bertambah sehingga perkembangan tanaman berjalan optimal. Williams, dkk (1993) dalam Banjarnahor (2018:11) menyatakan bahwa pemberian bahan organik mampu memperbaiki agregat tanah yang akhirnya akan meningkatkan 
Pemberian Pupuk Organik Cair Kotoran Kambing Dalam Meningkatkan Hasil Terung (Salanum melongena, L.)

perkembangan akar sehingga penyerapan unsur hara serta air menjadi lebih baik. Mayadewi (2007) dalam Banjarnahor (2018: 9) menyatakan bahwa di dalam POC mengandung unsur hara makro seperti nitrogen $(\mathrm{N})$, posfor $(\mathrm{P})$, kalium (K), kalsium (Ca), magnesium $(\mathrm{Mg})$ dan Belerang $(\mathrm{S})$ serta unsur mikro (besi, seng, boron, kobalt, dan molibdenium).

\section{KESIMPULAN DAN SARAN}

Hasil penelitian ini ditarik kesimpulan bahwa pemberian POC kotoran kambing dapat meningkatkan hasil tanaman terung dengan jumlah buah 4,90 dan berat buah $0,44 \mathrm{~kg}$, sehingga disarankan untuk memberikan POC kotoran kambing sebanyak $16 \mathrm{ml}$.

\section{DAFTAR PUSTAKA}

Banjarnahor, S.M. 2018. Pengaruh Penggunaan Pupuk Organik Cair (POC) Kotoran Kambing Terhadap Pertumbuhan Dan Produksi Tanaman Tomat Cherry (Solanum lycopersicumVar. Cerasiforme). Majalah Ilmiah Politeknik Mandiri Bina Prestasi. Volume: 7 No. 1Mei 2018. www.prestasi.ac.id. Diakses pada tanggal 1 Maret 2019.

Setyamidjaja, D. 2006. Pupuk dan Pemupukan. Jakrta: Simplex.

Soetasad,A.A., S. Muryanti dan H. Sunarjono. 2003. Budidaya Terung Lokal dan Terung Jepang. Jakarta: Penebar Swadaya. 